Journal of Southeast Asian

\title{
Navigating Multiple Worlds: A Qualitative Study of the Lived Experiences of Hmong Women Leaders
}

\author{
Lena Moua \\ lenamoua@netzero.com \\ Jim Riggs \\ California State University, Stanislaus, jriggs1@csustan.edu
}

Follow this and additional works at: https://docs.lib.purdue.edu/jsaaea

Part of the Education Commons

\section{Recommended Citation}

Moua, Lena and Riggs, Jim (2012) "Navigating Multiple Worlds: A Qualitative Study of the Lived Experiences of Hmong Women Leaders," Journal of Southeast Asian American Education and Advancement: Vol. 7 : Iss. 1, Article 2.

DOI: 10.7771/2153-8999.1044

Available at: https://docs.lib.purdue.edu/jsaaea/vol7/iss1/2

This document has been made available through Purdue e-Pubs, a service of the Purdue University Libraries. Please contact epubs@purdue.edu for additional information.

This is an Open Access journal. This means that it uses a funding model that does not charge readers or their institutions for access. Readers may freely read, download, copy, distribute, print, search, or link to the full texts of articles. This journal is covered under the CC BY-NC-ND license. 


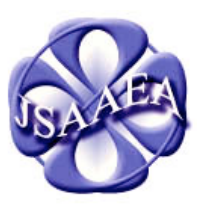

Volume 7 (2012)
Journal of Southeast Asian American

Education \& Advancement

WWw.JSAAEA.org
A peer-reviewed

scholarly journal

published by the

National Association

for the Education \&

Advancement of

Cambodian, Laotian,

and Vietnamese

Americans (NAFEA)

\title{
Navigating Multiple Worlds: A Qualitative Study of the Lived Experiences of Hmong Women Leaders
}

\author{
Lena Moua \\ Cesar Chavez High School, Stockton Unified School District \\ Jim Riggs \\ California State University, Stanislaus
}

\begin{abstract}
This article presents the findings from a narrative study that examined the leadership development and pathways of nine prominent Hmong American women leaders from Minnesota and California. Each of these women was able to break through the cultural and gender glass ceiling to become positional and influential leaders in mainstream American society. The study focused on the factors that contributed to the participants' leadership development; strategies used in attaining and maintaining leadership roles; and barriers each participant encountered on her path to becoming a leader. Important findings included the impact of poverty, the prominent role of education, inner strength the women possessed, importance of networking and support systems, and strong role models. Other factors included familial responsibilities, gender disparities, racism and ageism. The conceptual frameworks of Belenky, Clinchy, Goldberger and Tarule (1986), and Alon and Higgins (2005), were utilized to guide the analysis and presentation of each participant's life journey, and show the intersections between culture and feminist epistemology. The narrative case study approach included in-depth interviews, collective story mapping and re-narration techniques to explore the lives of these women leaders. One overarching goal of the study and this article is to create a greater understanding of complex issues and impediments associated with leadership development, with the hope of beginning a dialog that will help facilitate policy changes regarding developing and supporting minority women in leadership roles.
\end{abstract}

KEY WORDS: Bicultural, clan, filial piety, Hmong, influential leader, and position leader

SOBRERIGHISRESERVED Readers are free to copy, display, and distribute this article, as long as the work is attributed to the author(s) and the Journal of Southeast Asian American Education \& Advancement, it is distributed for noncommercial purposes only, and no alteration or transformation is made in the work. More details of this Creative Commons license are available at http://creativecommons.org/licenses/by-nc-nd/3.0/. All other uses must be approved by the author(s) or JSAAEA. 
Immigrants from around the world now make up nearly one eighth of the population of the United States (Suárez-Orozco, Suárez-Orozco, \& Todorova, 2008). One of the largest and growing subsets of immigrants is loosely grouped under the racial category of "AsianAmerican," which actually represents over 30 distinct ethnic groups who vary in religion, language, values, immigration history, and customs (Prosser, 2001).

A large number of research studies have been done on Asian Americans, focusing mostly on the more established, larger groups who immigrated to the United States voluntarily in search of job opportunities. These include Chinese, Japanese, Koreans, Filipinos, and East Indians. At the end of the Vietnam War in 1975, new refugee groups from the Southeast Asia region including Laotians, Cambodians, Vietnamese and Hmong were brought to the United States. These groups emigrated involuntarily due to political persecution and war, accounting for roughly $2 \%$ or less of the Asian American racial cluster (Ling, 2008). While their presence and influence in the United States continues to grow, they remain understudied and underrepresented in the body of research literature.

Many of the women from these new immigrant groups have historically experienced patriarchal and cultural oppression, particularly Hmong women. Traditional Hmong culture condones polygamy, bride prices, and other orthodox practices that devalue the female role. However, as noted by Yang (2008b), this is beginning to change. Hmong-American women have slowly begun to emerge as leaders, and hold professional positions in a variety of fields. Nearly three-fourths of all Hmong-American lawyers are women, and a handful of Hmong-American women have won political offices, most notably Mee Moua, who was elected to the Minnesota State Senate in 2002. The American Community Survey (2009) noted that $24.8 \%$ of Hmong women are in professionally related occupations compared to $21.6 \%$ of Hmong men.

There is a clear shift occurring in gender roles and expectations for Hmong living in the United States. Education and employment opportunities have given Hmong American women more choices to enhance their lives instead of being dependent on their male counterparts for support. However, like other minority women, women from the Hmong-American community must successfully navigate a complex bi-cultural and historically oppressive environment. The road to becoming a leader is often a lonely and difficult path where there are few role models and mentors, and very little guidance to assist these women. Therefore, it is extremely important to develop a better understanding of the challenges faced by the few women who have ascended into leadership roles and to discover first hand their stories as they moved into and through their leadership positions.

\section{Purpose and Focus of the Study}

The primary purpose of this study was to explore the experiences of nine Hmong women leaders and provide them with opportunities to discuss factors that have influenced their development and success as leaders. Having a better understanding of how these women were able to break through cultural and gender barriers, and ascend into significant leadership roles within both the dominant mainstream culture, and the Hmong-American culture would provide information essential for supporting, advising, educating, and empowering minority women towards achieving leadership roles, as well as add to the existing body of literature on Hmong culture and Hmong women. 
Two major conceptual frameworks addressing education, culture, feminism, and leadership factors were utilized to guide this research study. The study's methodology consisted of collecting in-depth narratives and drew upon a case study approach (Creswell, 2003).

In understanding women's experiences in leadership roles, many researchers have stressed the need to include feminist and culture perspectives (Banutu-Gomez, 2002; Moua, 2007). Recent studies addressing the roles of culture and feminism as significant contributors in leadership development, have argued that inclusion of cultural factors (gender, race, class, and religion) can bring change and dialogue to the existing andocentric paradigms of knowledge (Belenky et al., 1986; Bell \& Nkomo, 2001; Moua, 2007; Yoshikawa, 2006). The following research questions were formulated to guide this study:

1) What are the contributing factors to the participants' intellectual and moral knowledge and skill development, as well as the empowering tool(s) to aid them into their positions of leadership?

2) What contributed to the participants' acculturation experiences to make them leaders without being ostracized from one or both cultures?

3) How did the participants develop into their leadership roles and still negotiate the proper role as Hmong women in the Hmong community?

The participation of women in leadership positions represents less than $35 \%$ worldwide, even though they were estimated to comprise more than half of the world's population (McCormick-Higgins, 2005). In the United States, women make up $47 \%$ of the middle management positions, but drop to $17 \%$ at the executive management level (Guthrie \& Roth, 1999). This clearly points to the presence of a glass ceiling that is prohibiting women from moving up the organizational ladder (Crampton \& Mishra, 1999).

Recent studies on minority women's career advancement found that levels of education, job competency, strong work ethic, mentorship, effective leadership and communication skills, family support and strong ethnic identity all contributed to success, with education clearly ranking as the strongest factor (Moua, 2007; Wesley, 2008; Yoshikawa, 2006). Catalysts (as cited in Moua, 2007) noted and predicted that during the decades between 1992 and 2012, there will be a $75 \%$ increase in the number of Asian Americans in the workforce. Yet, there exists little research on the newer groups of Asian Americans, particularly Hmong women in leadership positions.

The Hmong population has made noteworthy progress in education attainment. By 2000, 11.7\% held Bachelor's degrees up from 3\% in 1990 (Hmong National Development \& Hmong Cultural and Resource Center, 2004). However, few Hmong women have been able to influence and gain power within the mainstream American culture, with only 5\% of Hmong women in management positions (Hmong National Development \& Hmong Cultural and Resource Center, 2004).

Montez (1998) noted that women emerging from minority cultures with longstanding cultural customs and gender expectations, such as Hmong women, are less likely to achieve. This raises several important questions. Could it be the immigration experiences and the substantial changes in the lives of women that hinder Hmong women's progression into leadership roles? What is happening to the social organization and marital relationships as more women transcend into leadership roles? Are the cultural differences in learning styles, gender roles and 
expectations in educational attainment and achievement, and Hmong parents' experiences and roles in their children's education, contributing to this low turnout of leaders?

\section{Conceptual Frameworks of the Study}

This study utilized two key conceptual frameworks from the scholarship on feminism and culture. These conceptual frameworks were chosen because they are widely accepted as appropriate lenses to view the inter-relationship of cognitive and emotional development of women and those from minority groups.

The first conceptual framework was based on a model by Belenky et al. (1986), which examined the stages that women go through to learn and construct knowledge, and is recognized as "an important investigation [means] into the processes of cognitive development because it focused on women, social classes, and differences that are significant in our society" (Love \& Guthrie, 1999, p. 17).

In the silence stage, women worry about verbalizing their thoughts, and speaking of themselves is almost impossible. They are obedient to authority, and developing a sense of voice, mind, and self are their ways of knowing in this stage. The next development stage is received knowledge, where women worry that their self-development might come at the expense of others, and they consistently look for others to grow intellectually.

In subjective knowledge, women distrust logic, analysis, and abstraction, and a sense of their own voice emerges. There is a shift in the source of truth; now, instead of the truth coming from external factors, truth is seen within the person and women become their own authorities. Procedural knowledge occurs when women learn to separate the knowing from their own established truths, and are able to criticize through careful observation and analysis. They have developed connected knowing (empathy and shared experiences) and separate knowing (separating feelings and emotions to obtain objectivity). The last stage, constructive knowledge, occurs when women learn to tolerate internal contradictions and ambiguity and to integrate external knowledge and self-knowledge.

Contrary to what many theorists have proposed about an individual having to pass through all the required stages of development to become transformed individuals, these Hmong women leaders became skilled role-players, hurtling back and forth through the five developmental stages, role-playing whichever stage was a higher priority.

The second conceptual framework considers culture and cultural intelligence, as suggested by Alon and Higgins (2005), to recognize how cultural factors significantly contributed to leadership. Hofstede (1991) defined culture as "mental programs or softwares of the mind [such as a person's] patterns of thinking, feeling, and potential acting which were learned in their lifetime" (p. 4). This conceptual framework was critical in understanding how culture affects women leaders' management and sustainability of their leadership roles.

\section{Assumptions and Limitations}

Two important assumptions in this research study were made. First, there are differences in gender expectations in the Hmong-American community that contribute to the underrepresentation of Hmong women in leadership positions. Second, values, norms, stereotypes, attitudes, and beliefs existing in institutions significantly impact women's development into leadership roles. The focus of the research study was primarily on position leaders and influential 
leaders and was limited to the voices of the nine Hmong women leaders from California and Minnesota, who were between the ages of 30 to 41, therefore it may not fully represent the experiences of older, more experienced women, who have been in leadership roles. The purposeful selection was based on securing the most qualified participants from a cross section of leaders who would be willing to share their lived experiences as leaders.

The selection process was based on maximum variation, where selected characteristics of the targeted population were used to acquire the most qualified participants. It is recognized that the participants' viewpoints may not fully represent the total population of Hmong women. In addition, the study focused on one group of minority women at a particular time in history, Hmong women in America during the 1990's through 2010. Therefore, the findings may not be fully applicable to women from other cultures and other times in history. The goal of this study was not to generalize, but to secure insights into the nine participants' lived experiences that could be used to generate themes and hypotheses for further research and investigation.

\section{Two Categories of Leadership}

Leadership is a process by which a person has the ability to influence others to accomplish an objective, and to direct them in ways that makes their unit more cohesive and successful (Bass, 1999). Wesley (2008) explains leadership as being “defined not by gender, but by a person's ability to grow, lead, reward, discipline, communicate, produce and meet organizational benchmarks" (pp. 41-42). While there are many categories for leadership, this study specifically focused on position leaders and influential leaders.

Literature on the Hmong from China to Laos clearly identified men as leaders, particularly Major General Vang Pao, and these leaders were predominantly position leaders. Thus, a position leader in this study was defined as someone who holds a leadership position and oversees a number of subordinates. Recently, there have been more modernized, high profile position leaders, both male and female, who have emerged in the United States; however, due to limitations noted in this research, the selection was based on maximum variation and the most qualified characteristics from the target populations from Minnesota and California.

An influential leader was defined as someone who has substantially influenced her respective field, community, or society. There have been and are still many influential leaders in the Hmong community, however, the Hmong community has always discounted both male and female influential leaders.

\section{Hmong Immigration in the United States}

When Laos fell to the communists in late 1975, the Hmong who sided with the Royal Lao government became political refugees and began to move to other countries including the United States. The migration to the United States happened rather quickly starting in 1976 with an estimated 750 Hmong arriving in the United States (Yang, 2001). The Hmong-American population grew from 94,439 in 1990 to 186,310 in 2000 (Yang, 2008a). The growth trend continued with the 2010 Census showing 260,067 reporting Hmong as their ethnicity. Both the 2000 and 2010 Census revealed that the largest number of Hmong live in clusters in a handful of states with nearly 35\% in California and over 44\% in the upper Midwest states of Minnesota and Wisconsin (Center for Hmong Studies, 2011). 


\section{Traditional Gender Roles and Expectations in the Hmong Community}

In Hmong society, clans provide a foundation for legitimate marriages through the rule of exogamy. Donnelly (1994) noted that one of the main functions of the clans is to regulate marriage by prohibiting unions within the clan and to regulate social reciprocity. Thus, the last names of the Hmong are the name of the husband's clan. Traditional Hmong marriages served many important functions including uniting a man and a woman for the purposes of procreation and economic production, and to create reciprocal economic, political, and ceremonial ties between respective clans (Moua, 2003). Due to the emphasis on the male's role in the family, women often maintained conservative roles with little authority except over children and other women of lower status while men took to the agricultural fields, performed heavy labor, and were the ones involved in major political, social and economic transactions (Moua, 2003). Even in modern days, these traditional gender roles continue in the Hmong-American community.

In addition to valuing the clan structure, the Hmong believe in filial piety, a concept originating from Confucianism requiring each person to "love one's parent, being respectful, polite, considerate, loyal, helpful, dutiful, and obedient" (Huang, n.d.). Respect is valued over asserting oneself, and role fulfillment and obligation are expected rather than personal development and achievement.

The cultural practice of saving or losing face is also of high importance for the Hmong. Any form of disgrace a person experienced could disrupt the entire clan. The individual is taught to think of the community and family before self and bring honor to everyone in the Hmong community. In the Hmong-American community the ideology of filial piety can be found in most, if not every, family. Parents still stress the importance of respecting adults, not questioning authorities, and bringing honor to the family. However, what may seem as positive, respectful behavior within the traditional Hmong culture may create a challenge for someone in a leadership position where questioning authority or asserting oneself is necessary and expected behavior.

Although Hmong parents in the United States are characterized as valuing filial piety, promoting interdependence among family members, and emphasizing traditional cultural practices (Supple, McCoy, \& Wang, 2010), Hmong youth have acculturated through their educational experiences towards the belief that they are entitled to more autonomy in decisionmaking and peer association (Xiong, Eliason, Detzner, \& Cleveland, 2005). Underage marriage, paying bride prices, and patri-local residence are still practiced, however, the union of two people is now out of free will and residing with extended families under one roof is more out of necessity or personal choice than adherence to tradition.

\section{Leadership Designations Within the Hmong Community}

Literature on the Hmong from China to Laos clearly identifies men as the recognized leaders, primarily serving as leaders within large and small clans (Lee, 2005). After more than three and half decades of living in the United States, a variety of leaders have emerged in the HmongAmerican community. According to Yang (2008b) "Hmong-American community leadership had evolved in three major groups, the older [more traditional] leaders; the middle-aged, middleof-the-road leaders; and the younger, modernized leaders" (p. 241). While the older, traditional leaders are still respected, the middle-aged leaders have formulated their own identity, and the younger, modernized leaders have emerged to share much of the power. Younger leaders are 
more literate in the English language and have embraced a number of mainstream American values and practices.

\section{Feminist Epistemology, Biculturalism and Leadership}

For centuries, women have maintained conservative positions including schoolteachers, maids, homemakers, and other subservient roles thought to be inherently present in their genetic makeup. This is best viewed through role theory, which defines how individuals are expected to behave, and how individuals in specific roles perceive what they are supposed to do (Toren, 1973).

McMaster and Randall (1995) argued that in gender-based social traditions women are discouraged from seeking leadership positions. For bicultural women, there exists a kind of double glass ceiling, which brings a number of barriers related to sexist and cultural biased attitudes that prevent or delay advancement (Crampton \& Mishra, 1999).

Over the last century the perception of Asian Americans has transformed "from 'uneducable heathens' to the model minority" (Montez, 1998, p. 3). Thus, the term model minority was used to stereotype Asian Americans and assumed by many that they did not need academic or professional guidance or support. This resulted in society ignoring the talents and leadership development needs of this group. In addition, Asian-American women who seek professional positions and exhibit ambition will likely be viewed as having undesirable Asian female traits (Montez, 1998). The negative stereotypes, cultural discrimination and gender bias that Asian-American women experience from their own community and that of the mainstream community are formidable and continue to impact their advancement.

Patriarchal orientation, specifically deference to older, male colleagues, has been a significant challenge for many Asian-American women in developing career advancing relationships and networks. Traditionally, Asian American women have been indoctrinated to play subservient roles and tend to the needs of others, and not permitted to become leaders. However, over the past 50 years women have been increasing their presence in the workforce and are "creating social and economic changes and working towards equal rights" (Sykes, 2008, p. 5). Clearly women, whether they are bicultural or not, have fought against the belief that men were more qualified to be leaders, and have proven that women can and are effective leaders. Other factors that prevented women from ascending to leadership positions were, as Sykes (2008) argued, "responsibilities for children and family requiring absence from the workplace which gave male coworkers more opportunities" (p. 6). Many women would agree that they are the backbone of the family and therefore, their highest priority. However, researchers have argued that this act of prioritizing the family first contributes immensely to their effective leadership style.

Both men and women transfer these personalities into the leadership arena. As leaders, women tend to place a greater emphasis on being humanistic, social, inclusive, and acting in cooperative and collaborative ways; whereas, men's traits are seen as confident, assertive, ambitious, and independent. In addition, women tend to display greater emotional intelligence in the workplace (Goleman, 1998). Many women have become interactive leaders constantly working with subordinates and sharing power, generating trust, and motivating workers to achieve individually. 


\section{Research Design and Participant Selection}

This study occurred across a two-year span, which began with the email correspondences expanding to the initial one-hour interviews with each participant to the conclusion of the research. Nine Hmong women leaders were selected for this study that represented a distribution of professions including business, politics, education, health professions and nonprofit organizations. A number of the participants were identified from newspapers and news reports via Internet, magazines, and television reports.

The second source used to identify participants was through professional organization nominations and recommendations of colleagues or professors. In addition, letters were sent to professional Hmong organizations seeking nominations for this study. Once possible participants were identified, letters where sent asking selected individuals to participate in the study. Nine individuals agreed to participate who fit the criteria of the study including three that were identified as "influential" leaders and six that were classified as "position" leaders. Table 1 below provides information about the participants.

Table 1

Participants in the Study

\begin{tabular}{|c|c|c|c|c|}
\hline Name of Participant & Type of Leader & Leadership Title & $\begin{array}{l}\text { Place of } \\
\text { Residence }\end{array}$ & Marital Status \\
\hline Bao Vang & Position & $\mathrm{CEO} /$ & $\mathrm{MN}$ & Married \\
\hline Fenglaly Lee & Position & $\begin{array}{l}\text { Businesswoman } \\
\text { Obstetrician/ } \\
\text { Gynecologist }\end{array}$ & $\mathrm{CA}$ & Married \\
\hline Kao Kalia Yang & Influential & Nonfiction Writer & $\mathrm{MN}$ & Single \\
\hline Kaying Hang & Influential & $\begin{array}{l}\text { Senior Program } \\
\text { Officer }\end{array}$ & $\mathrm{MN}$ & Single \\
\hline Kazoua Kong-Thao & Position & $\begin{array}{l}\text { Chairman of School } \\
\text { Board of Education }\end{array}$ & $\mathrm{MN}$ & Married \\
\hline Koua Jacklyn Franz & Position & $\begin{array}{l}\text { Director of Nonprofit } \\
\text { Organization }\end{array}$ & $\mathrm{CA}$ & Married \\
\hline Mee Moua & Position & $\begin{array}{l}\text { Senator/State } \\
\text { Legislator }\end{array}$ & $\mathrm{MN}$ & Married \\
\hline Misty Her & Position & $\begin{array}{l}\text { Elementary School } \\
\text { Principal }\end{array}$ & $\mathrm{CA}$ & Married \\
\hline Pakou Hang & Influential & $\begin{array}{l}\text { Campaign } \\
\text { Organizer/Activist }\end{array}$ & $\mathrm{MN}$ & Single \\
\hline
\end{tabular}

\section{Data Collection and Analysis}

Each participant completed a demographic questionnaire and consent form prior to the scheduled interview. The participants were encouraged to select the locations for the interviews. Some participants were more comfortable meeting at coffee houses while others preferred the office or home setting. An in-depth, semi-structured interview process that included open-ended questions 
was used to explore multiple identities, managing work and family, the influence of culture, and individual challenges and limitations. Interviews were completed face-to-face and audio recorded.

At the beginning of the interview, a brief synopsis of the purpose of the research and the study's conceptual framework were reviewed with each participant. The following three major questions were used to guide the interview:

1) What are the contributing factors to the participants' intellectual and moral knowledge and skill development, as well as the empowering tool(s) to aid them in their positions of leadership?

2) What contributed to the participants' acculturation experiences to make them leaders in the macro-culture without being ostracized from one or both cultures?

3) How did the participants develop into their leadership roles and still negotiate the proper role as Hmong women in the Hmong community?

Participants were encouraged to unveil their life experiences from whichever point in their life they preferred to disclose. The interviewer listened, observed, and interjected periodically during the interview process for clarifications and to acquire information needed for the study. When the participants requested confidentiality, the recording device was stopped until the participants were comfortable being recorded again. The interviewer only took limited notes permitting her the opportunity to critically listen and observe the participants' behavior and to connect with the participants on a more personal level.

A transcription agency could not be utilized since eight of the participants responded half the time in Hmong and the other half in English, and one participant elected to speak entirely in Hmong throughout the interview. Therefore, the interviewer, who is fluent in Hmong, transcribed all nine interviews.

A three-step process as suggested by Strauss and Corbin (1990) for data-reduction was utilized to analyze the data beginning with open coding to identify key themes. Next was axial coding, where each of the nine participants' stories was presented as a separate, detailed case study. The final step, selective coding, involved identifying central themes and subthemes in the case studies. Investigator triangulation and data triangulation was used to compare the thoughts and ideas of other observers on the findings and results of the research.

Colleagues, family members, and university faculty were utilized as external auditors. In addition, outside readers were used to assist with data reduction and results as well as the development of themes and interpretation of the findings. Outside readers who are literate in the Hmong language were also used to ensure accuracy of the transcripts. Participants also reviewed the transcripts. The texts were then downloaded into the research software Dedoose to evaluate the data and assist with the identification of patterns and themes.

\section{Re-narration Overview}

To provide personal voices and insights into the complexities of the participants' lives and to reveal the impediments these women leaders have been challenged with, a re-narration of each participant's life story was provided. Four headings helped categorize and gave individualized voices to the participants' life experiences throughout the re-narration: life journey, selfdiscovery, balancing a bicultural identity, and leadership attainment and experiences. However, 
due to the length of the re-narration of each of the participant's story, they have been omitted from this article; these re-narrations can be found in Moua (2011).

Gilika (2009) noted that having "a collective story map [would] allow for some comparison between participants' stories, which provided understanding of how each participant's past and present experience and future intentions impacted leadership roles" (p. 136). A collective story map is provided in place of the re-narration to purposefully summarize and compare the participants' life stories (see Table 2).

Table 2

Collective Story Map

\begin{tabular}{|c|c|c|c|c|}
\hline Participant & Life Journey & Self-Discovery & $\begin{array}{l}\text { Balancing a } \\
\text { Bicultural Identity }\end{array}$ & $\begin{array}{l}\text { Leadership Attainment } \\
\text { \& Experiences }\end{array}$ \\
\hline Bao Vang & $\begin{array}{c}\text { - married } \\
\text { underage }\end{array}$ & $\begin{array}{l}\text { - struggles } \\
\text { made her } \\
\text { stronger }\end{array}$ & $\begin{array}{l}\text { - role play } \\
\text { - task master }\end{array}$ & $\begin{array}{l}\text { - promoted } \\
\text { - a risk taker }\end{array}$ \\
\hline Fenglaly Lee & $\begin{array}{l}\text { - used the } \\
\text { library as an } \\
\text { escape }\end{array}$ & $\begin{array}{l}\text { - aspired to be } \\
\text { a doctor at } \\
\text { young age }\end{array}$ & $\begin{array}{l}\text { - lost the Hmong } \\
\text { language }\end{array}$ & $\begin{array}{l}\text { - self-develop } \\
\text { - paid own bride price }\end{array}$ \\
\hline $\begin{array}{l}\text { Kao Kalia } \\
\text { Yang }\end{array}$ & $\begin{array}{l}\text { - family as } \\
\text { role model }\end{array}$ & $\begin{array}{l}\cdot \text { love the } \\
\text { Hmong } \\
\text { language }\end{array}$ & $\begin{array}{l}\text { - separate Hmong } \\
\text { and English }\end{array}$ & $\begin{array}{l}\text { - self-develop } \\
\text { - embraced identity }\end{array}$ \\
\hline $\begin{array}{l}\text { Koua Jacklyn } \\
\text { Franz }\end{array}$ & $\begin{array}{l}\text { - married } \\
\text { interracially }\end{array}$ & $\begin{array}{l}\text { - advocated } \\
\text { healthy } \\
\text { marriages }\end{array}$ & $\begin{array}{l}\text { - paid own bride } \\
\text { price }\end{array}$ & $\begin{array}{l}\text { - promoted } \\
\text { - mentoring and } \\
\text { networking impacted } \\
\text { her }\end{array}$ \\
\hline Mee Moua & - a lawyer & $\begin{array}{l}\text { - education } \\
\text { important }\end{array}$ & $\begin{array}{l}\text { - see self as a } \\
\text { bridge }\end{array}$ & $\begin{array}{l}\text { - elected } \\
\text { - leadership changes } \\
\text { people }\end{array}$ \\
\hline Misty Her & $\begin{array}{l}\text { - impacted by } \\
\text { cultural } \\
\text { gender } \\
\text { expectations }\end{array}$ & $\begin{array}{l}\text { - aspired to be } \\
\text { a teacher }\end{array}$ & $\begin{array}{l}\text { - father wanted a } \\
\text { son }\end{array}$ & $\begin{array}{l}\text { - promoted } \\
\text { - led by example }\end{array}$ \\
\hline Pakou Hang & $\begin{array}{l}\text { - management } \\
\text { training } \\
\text { consultant }\end{array}$ & $\begin{array}{l}\text { - attended } \\
\text { private } \\
\text { schools }\end{array}$ & - expected to wed & $\begin{array}{l}\text { - self-develop } \\
\text { - education important }\end{array}$ \\
\hline
\end{tabular}

Findings

After coding, categorizing, and analyzing the transcriptions and field notes, three major themes and several subthemes emerged (see Table 3) that addressed the research questions. Each of the three major themes also yielded various subthemes. 


\section{Theme 1: Factors Contributing to Participants' Leadership Growth}

Participants noted various motivations that contributed to their desire to be leaders but two significant contributors were their cultural background and poverty experiences while growing up.

Subtheme 1.1: Impact of cultural background. Emerging from a patriarchal culture, these women have been tremendously influenced by their cultural backgrounds to become leaders. They have repeatedly witnessed the oppression and limitations placed on themselves and the women in their lives. Thus, participants felt an urgent obligation to be agents of change. Being leaders, paving the way for others, and clarifying the misconceptions of the Hmong culture were the initial steps to generating change. Although participants have journeyed fullcircle as bicultural women, according to the five stages of development suggested by Belenky et al. (1986), they still find themselves in an "in-betweenness" situation and developed the ability to play many different roles. They were all adept at navigating throughout each of the developmental stages as necessary.

Table 3

Emerged Themes

\begin{tabular}{|c|c|c|}
\hline Themes & Main Content & Subthemes \\
\hline $\begin{array}{l}\text { 1. Factors that contributed to } \\
\text { participants' leadership } \\
\text { development }\end{array}$ & $\begin{array}{l}\text { Motivators that influenced } \\
\text { participants' decision into } \\
\text { leadership }\end{array}$ & $\begin{array}{l}\text { 1.1 Impact of culture } \\
1.2 \text { Experiences with poverty }\end{array}$ \\
\hline $\begin{array}{l}\text { 2. Strategies in attaining and } \\
\text { maintaining leadership roles }\end{array}$ & $\begin{array}{l}\text { Strategies that helped } \\
\text { participants acquire and } \\
\text { sustain leadership roles }\end{array}$ & $\begin{array}{l}\text { 2.1 Educational as liberator } \\
\text { 2.2 Inner strengths } \\
\text { 2.3 Networking and being } \\
\text { accessible } \\
\text { 2.4 Having support systems/ } \\
\text { role models }\end{array}$ \\
\hline $\begin{array}{l}\text { 3. Barriers participants } \\
\text { encountered }\end{array}$ & Roadblocks encountered & $\begin{array}{l}\text { 3.1 Familial responsibilities } \\
\text { 3.2 Something gained but } \\
\text { something lost } \\
\text { 3.3 Gender disparities } \\
\text { 3.4 Racism and ageism }\end{array}$ \\
\hline
\end{tabular}

In the silence stage of their development, participants adhered to the traditional cultural gender expectations. For instance, even as leaders, participants practiced being silent, yet they have modified this silence to their advantage. Participants noted that they carefully conducted a daily balancing act to juggle the Hmong and mainstream cultural expectations. Participants navigate their various roles and cultural expectations utilizing cultural intelligence. Earley and Masakowski (2004) described cultural intelligence as the ability to interpret, construct, and reconstruct themselves and their cultures to adjust to both cultures. For instance, Bao learned to exploit the silence while simultaneously actively observing and listening to her employees and coworkers when they congregated. She contended that many people deemed being actively silent 
as difficult to accomplish, but for her, it has been culturally rooted, so she was simply amending it to correspond to her wishes.

Participants obtained their leadership roles but never at the expense of their loved ones. Self-sacrifice for the betterment and interest of the children has been a longtime and enduring cultural practice in the Hmong community. For instance, before Misty embarked on her promotion as the youngest principal in her district, she had to thoroughly confer with her spouse about the many long hours she might have to devote to her position, as well as the number of male coworkers she would encounter.

In the third stage, subjective knowledge, these women gradually cultivated their own voices, determined their own paths, and secured experiences along the way. These Hmong women leaders also progressed through this stage of development, but earlier than most women their age. They illustrated this in their dealings with the issue of underage marriage. The continuous anxiety during the participants' adolescent years induced them to take radical measures to determine the course of their lives. Misty recalled evading third grade to speed up her years in school as a means to elude early marriage, and Fenglaly noted how she dreaded underage marriage to such a great extent that she took the initiative as a seventh grade student to convince the high school principal to enroll her the following school year as a freshmen so that she could accelerate through high school.

Even as leaders, these participants were frequently reminded of the Hmong's traditional gender expectations. Pakou, Kaying, and Kao, the three unmarried participants, openly discussed their parents' wishes for them to wed and preserve the family line. When Pakou campaigned for a political position and was unsuccessful, she reasoned that the Hmong community was not supportive of her candidacy, primarily because she was a 30-year-old unmarried woman with no children.

In their professional trades, these women leaders had to answer to criticism over some of the Hmong's eccentric traditional practices. For instance, Mee, in her leadership responsibilities, was under attack on the underage marriage issue. When Mee volunteered to assist a Caucasian colleague in designing a legislative bill to address underage marriage, she was questioned and accused by the media of aiding and abetting terrible acts against young girls in the Hmong community.

In the fourth stage of development, procedural knowledge, these women became more skeptical and began to rely on their own acquired life experiences. Mee noted that she was first and foremost a bridge between the macrocommunity and the Hmong community. Her leadership status was extremely significant when the Hmong culture and community were being targeted, since she had the unique opportunity to provide accurate perspectives on the subject.

Finally, as they entered stage five, constructive knowledge, these women developed a greater sense of self-worth, had more tolerance for contradictions, and became more competent to examine, question, and embrace the world from an unbiased and unprejudiced viewpoint. Being more educated translated into being more methodical and aware of the influences Hmong culture had on them.

From their cultural indoctrinations, these Hmong women leaders observed and became skilled in actively listening, passively learning, and being expert persuaders. Participants slowly developed their own voices and discovered their own passions, defining their subjective knowledge. Although they were conscious of the criticism from the Hmong community, they persisted in pursuing their visions, believing change would emerge in the near future. 
Being bicultural did not weaken the participants, but instead, it enhanced and refined their leadership skills and broadened their perspectives on diversity in the community. They were able to navigate between their culture and the macroculture, and still balance their responsibilities in both worlds. In turn, they achieved a greater, more in-depth understanding of the Hmong culture, and they learned that through leadership, they could help create the correct image of the Hmong community as well as lead the way for others to follow. They uniquely defined themselves and enhanced their leadership abilities by adapting to American ideals, while filtering out inappropriate cultural practices such as polygamy, levirate, and patri-local residence.

Subtheme 1.2: Experiences with poverty. All nine participants saw how their parents struggled with the English language, and how many of them were demoted in their status by being in a foreign country. Although some of the participants' parents resorted to basic farming and raising livestock for a living, they still encouraged educational attainment and successful careers for their children. Later, even as successful leaders in their fields, most of the participants still found the time during weekends and holidays to assist their parents in selling at farmer's markets, or tending to the crops.

All nine participants had epiphanies about their participation in various social systems available for refugees at one time. Products of welfare, and in a few cases public housing projects, the participants saw that they must attain success to better their lives. Bao recalled raising 13 children, 10 of whom were her husband's siblings that she had inherited after her inlaws divorced. Although she and her family benefited from the social systems, she, like the other participants, was able to improve her family's living condition by attaining a career and leadership role.

\section{Theme 2: Strategies to Attain and Maintain Leadership Roles}

Other research studies have found similar trends in accordance to the theme of attaining and maintaining leadership roles. Moua (2007), for instance, conducted a multi-case study on 10 bicultural women to explore their leadership construction and practices; she discovered that bicultural women experienced an extremely biased leadership system. However, they persisted due to a strong family support system and their personal development of balancing roles. Yoshikawa (2006) also conducted a similar study exploring Hmong women's traditional roles as they affected Hmong-American women leaders' emergence into leadership roles, and concluded that an ethnic identity blended with the presentation of personal individuality was what made Hmong-American women successful. Bell and Nkomo (2001) conducted a related study on African-American women and discovered that they too encountered stereotypes, gender, and ethnic assumptions; African-American women also faced multiple stressors from juggling multiple and conflicting roles.

In attaining their leadership skills and sustaining their leadership positions, participants in this study cited their education experiences, inner strength, networking and transparency abilities, and having support and role models as important factors that enabled their career advancement and sustainability.

Subtheme 2.1: Education as liberator. All of the participants' parents understood very well that education was for the elites in their native country. Only three participants' mothers received some form of elementary education and six participants' fathers received some form of 
incomplete secondary education. All nine participants' maternal and paternal grandparents received absolutely no education at all. Thus, it is no wonder that the United States was the land of opportunity to all the participants. They saw education as the factor that would liberate them from their impoverished living conditions. All of the participants pointed out the importance of a formal education and considered it as the primary vehicle to women's career advancement.

Subtheme 2.2: Inner strength. Participants shared that the motivation to seek leadership positions came from their inner strength, which they defined as having courage, taking risks, determination, persistence, passion, and confidence. However, what distinguishes an ordinary person or an average leader from an effective leader is their passion to be individually unique - a flame that burns continuously throughout their lives. Each of the participants had a passion to do what they were doing. Whether success meant better living conditions or power, they pursued success relentlessly, and even after attaining leadership positions, they continued to seek higher goals.

Subtheme 2.3: Networking and being accessible. These Hmong women leaders obtained and maintained their leadership roles through their unique ability to network and be transparent. As early as elementary school, they were actively involved in leadership positions and associating with key players in their community. For instance, with the exception of Bao, all of the participants were highly involved in school activities such as sports, student council, internships and clubs. These women made themselves visible to those in leadership positions, and all focused on building professional networks.

Subtheme 2.4: Having support systems and role models. Family and kinship systems played a critical role in the advancement of these women's careers. Even though family and kinship are only recognized through the male's line, without the support of their families, parents and spouses these nine Hmong women leaders would not be the leaders they are today.

The three participants who were single at the time of this research study noted how their parents stepped away from the cultural norm to permit them to attend colleges and internships all over the country. The six participants who were married maintained that they are the most fortunate compared to other married Hmong women because their spouses still supported their endeavors, despite criticisms from the Hmong community. In addition, most of the participants had one or more role models in their lives who either led the way or encouraged them to succeed academically. Mee, Pakou, and Kaying had their cousin Cy Thao, the first Hmong man in the U.S. House of Representatives, and a few others had male relatives who were doctors. Also, since the three were related, Pakou saw her older sister, Kaying, and cousin Mee as role models as well.

Having a benevolent mother or grandmother as a role model helped some of these women. Kazoua recalled her grandmother being her hero because of her self-sacrificing strength in raising nine children as a single mother. Kazoua also saw her mother as her role model, a woman who wanted her to attain an education because she was denied one. Kao Kalia maintained that her parents and grandparents, particularly her grandmother, were her role models.

Nonetheless, levels of encouragement received from their parents were not the same. Some of the participants came from an upbringing where obtaining an education was inevitable, while some participants' parents were more traditional and were discouraging at times. Yet, 
participants who lacked the parental support received the needed encouragement from teachers in school and colleague.

\section{Theme 3: Barriers that Confront Participants}

Barriers identified by participants were associated with familial responsibilities, something gained and something lost, gender disparities and sexism, and racism and ageism in the Hmong community and macroculture.

Subtheme 3.1: Familial responsibilities. All of the participants noted that having leadership roles entailed numerous responsibilities. Regardless of their leadership roles, these women were still caretakers of the household and compelled to fulfill both family and work obligations. The married participants noted that their demanding work hours meant their spouses had to contribute to the household responsibilities, and their spouses were accommodating in sharing duties. Having children also added to the challenge. Oftentimes, participants' spouses or family members had to contribute to raising the children.

The men seemed to have lost most of their traditional economic and social authority and were redefining their roles to help the family as the women sought employment. Several of the participants reported that because of this shift in power dynamics they were greatly criticized in the Hmong community, so participants cleverly role-played the submissive wife at Hmong social gatherings just to conform. Kazoua noted that it was convoluted to discern and perform one's role consistently, and sometimes her tendency to share automatically emerged. She recommended rehearsing to ensure flawlessness.

Most of the participants had multiple role responsibilities prior to achieving their leadership positions. Bao, for instance, noted that socialization and participation were impractical. Not only did she have to manage home and work, but she also had to balance the Hmong culture as well. She claimed, "The Hmong community loves to socialize on the weekend, so being the oldest daughter-in-law in the family, I'm expected to be everywhere and help everyone."

All of the women cited difficulties trying to balance personal life with the demands of their leadership roles. Some participants noted the lack of time for relationships and for themselves, and some wished for the experiences of an ordinary life. Other participants even noted leadership responsibilities being incompatible with their home life. Participants concurred that as women and bicultural, they had to put forth additional efforts and expand beyond their peers to be successful. Not only did they have to balance their personal and professional lives, they also had to juggle their roles as wife, mother, and sister in the Hmong community.

Subtheme 3.2: Something gained but something lost. All of the participants agreed that leadership is a lonely road; but leadership has changed them for the better. Most of the participants concurred that they benefited from being bicultural. Having a dual identity provided the participants with the opportunity to be a bridge to the Hmong community and that of the macrocommunity. Thus, ethnic identity added to self-efficacy was what made these women so successful within the two distinctive cultures.

Participants' experiences with poverty also provided them genuine life experiences. Subjugating the harshness of reality presented them with more credibility in their leadership 
roles, as well as encompassing an unparalleled frame of reference to comprehend their colleagues and employees at a more compassionate, empathetic level.

Nevertheless, there were a number of things lost in the process of attaining success. Suárez-Orozco et al. (2008) maintained that many immigrants new to a country may begin by being "folk" or "circumstantial" bilinguals, acquiring the native language for the sake of survival (p. 151). However, at some point, their interpersonal communication skills and cognitive and academic language in the native language might surpass their primary language. Some of the participants noted how they were so obsessively focused on mastering the English language, they had neglected their own native language.

In essence, most of the participants conceded that something had to be forfeited for the attainment of something else. For a few of the participants, not having the time to find a soul mate or start a family was the cost. Being bicultural meant they were in-between worlds. This "in-betweenness" only made the sacrifice more complicated since the person could not entirely elude one culture or the other. They needed to navigate those multiple worlds to find an equal balance of success from one world to another. Success came at a cost for many of these women. Kazoua noted that many Hmong women who are considered successful in the macrocommunity are not very successful in the Hmong community and vice versa.

Subtheme 3.3: Gender disparities. All of the participants attested to some type of gender disparity in the Hmong culture. Participants noted how gender disparity had left a profound impression on their decisions and ambitions to seek leadership opportunities. One participant noted that the leadership arena was male-dominated, and suggested that before any women challenged the leadership field, they must establish a trust factor in their personal relationships. As accommodating as their spouses were, there was still the element of insecurity when a woman was constantly working unaccompanied by a man or several men.

Subtheme 3.4: Racism and ageism. Most of the participants discussed some form of racism and ageism in the Hmong community and macroculture. Most of the position leaders noted that they experienced ageism in the workplace more often than racism while most of the influential leaders experienced both racism and ageism on an equal basis. Although racism cannot be a justification in the Hmong community because the participants came from that same ethnic background, it can be said that all of the participants experienced some form of criticism from their own Hmong community on a more regular basis than from the macrocommunity. Ageism is also an enormous phenomenon in the Hmong community. Since the Hmong culture preached respecting elders and its power structure was based on a hierarchical pyramid from the oldest to the youngest, these women's leadership positions became insignificant most frequently in the Hmong community.

In the workplace, most of the participants had obtained their leadership status in their twenties or thirties, which contributed to their experiences with ageism. For instance, Kaying attained her initial leadership role when she was only 23 years old. She recalled being challenged by her much older Caucasian secretary. On the same note, Misty also recalled her earliest experience as the youngest principal at the age of 29, when she was challenged at her first staff meeting. If their age did not make trouble, it was their petite build. Kao Kalia remembered when she was misidentified by campus staff members as a student, even though she was the keynote speaker for their main event. 


\section{Interpretation and Discussion}

Three major textual themes and ten subthemes emerged; thus, it is crucial to link their relevance to the research questions. Thereby, the themes and subthemes as related to the three major research questions are explained as follow:

Addressing Research Question 1: What are the contributing factors to the participants' intellectual and moral knowledge and skill development, as well as the empowering tool(s) to aid them into their positions of leadership?

All of the participants cited experiencing poverty in one way or another. They witnessed how their parents struggled with financial and language difficulties and how they resorted to utilizing the social systems including housing projects and welfare. As a result, participants recognized early on that they could not tolerate the type of laborious jobs that their parents worked, nor could they endure surviving daily on governmental support. Recognizing that they had distinctive inner strengths, participants strove to achieve positions that would better their families' lives.

Participants turned to education as the liberating empowerment tool. Education became an introduction to new rules and values and the route that opened doors to opportunities for participants to escape a life of poverty. The educational settings helped many of the participants to negotiate rules, facilitate the mainstream culture, and alter their values. In addition, their educational environment allowed them to identify role models to emulate. Participants also learned networking through internships and other field experiences, as well as job opportunities that emerged.

Addressing Research Question 2: What contributed to the participants' acculturation experiences to make them leaders in the macroculture without being ostracized from one or both cultures?

All of the participants had the aspiration to thrive in the macroculture because of poverty; thus, they pursued the American Dream relentlessly in their attempts to assimilate. However, participants believed they could never be fully Americanized because they were bounded by their Hmong identity. Most of the participants noted being misidentified as another ethnicity or stereotyped because of the mainstream's limited knowledge of the Hmong community and culture. Some participants cited examples where they were questioned and contested because they were a minority.

Ageism also became a dominating factor that participants had to endure in both the Hmong and mainstream community. Because the Hmong culture rendered the elders as superior in status, all of the participants still had to portray the subservient roles when at Hmong social events despite their leadership attainments. Nonetheless, the participants emerged with cultural intelligence, stronger, wiser, more compassionate, and more knowledgeable in their fields of practice as well as being more tactful in their responses to future challenges as a result of experiencing racism and ageism. 
Addressing Research Question 3: How did the participants develop into their leadership roles and still negotiate the proper role as Hmong women in the Hmong community?

Most of the participants concurred that although their families realized the importance of obtaining an education and a stable career, traditional Hmong cultural practices still had a major impact on their lives. There were familial responsibilities such as child rearing, household chores, helping the family with parties and farming, and maintaining a career that participants had to balance.

Participants learned to play multiple roles. Those who were married shared household chores with their spouses. When they were in the mainstream community, they were vocal leaders, oftentimes facilitating, directing, and making the final decisions. Participants who were single still played the submissive, dutiful daughter role when they were with their parents in Hmong social gatherings. However, when they were amongst coworkers, employees, or colleagues, they wore a different mask. Even as leaders, these women still adhered to numerous Hmong rituals and habits such as shopping at Hmong stores, attending Hmong funerals, and getting their vegetables from the farmer's markets.

Eight of the participants noted that Hmong culture was still male-dominated, and patriarchal norms still governed their lives. Adaptation simply made it a requirement to change their lifestyles and blend in the American lifestyle for the survival of the family. Thus, in the Hmong culture, there exists another invisible layer of the glass ceiling on top of the already existing glass ceiling in the community. All of the participants lead only in the macrocommunity. The majority of the Hmong population still has mixed feelings about women in power. This leaves the curious question of how much more respect would be accorded to these individuals had they been male.

\section{Recommendations}

The findings of this research study demonstrate that Hmong women in leadership positions experience a multitude of challenges while attempting to achieve leadership status. Making one general recommendation for everyone is not advisable because each group of people needs to be held accountable differently to ensure empowerment of women into leadership positions.

\section{Recommendations for Hmong Men}

There are numerous male mentors in the Hmong community. Male role models who have inspired and paved the way for the Hmong community both as position and influential leaders, who have also explicitly encouraged women to follow in their footsteps such as Cy Thao (the first Hmong in the United States House of Representative) and Neal Thao (the first Hmong to serve on the St. Paul, Minnesota School Board) were alluded to in this study. Also obvious are the men who have stepped out of the norm, such as the spouses of participants in this study who have allowed and supported their wives to obtain higher education, or seek leadership positions despite criticisms from the Hmong community. Thus, it is recommended that similar studies be conducted on these men to obtain the male's perspectives and voices, which could be added to the women's voices in this research study. An additional recommendation would be to adjust and adapt to the changing times. Hmong men should consider sharing equal responsibilities in the 
home and public sphere, as well as allowing their women to seek opportunities to enhance themselves and their contribution to the family unit.

\section{Recommendations for the Hmong Community}

Yang (2004) noted that Hmong children learn the American culture very quickly and many have either abandoned the Hmong culture and language completely or have displayed their disrespect to the Hmong culture and community openly. Yet, a closer examination will confirm that no matter what roles they play or what route they pursue, they can never escape the Hmong identity. It is recommended that all Hmong youth embrace their cultural heritage including relearning the Hmong language, learn to utilize the positive cultural practices, and modify others to balance the bicultural identity.

For Hmong parents, it is imperative to understand that life in the United States is uniquely different from Laos. Both sons and daughters need to have equal access to opportunities, especially education opportunities. When the daughters are helpless, experiencing poverty or suffering, they are still their parents' daughters and will surely turn to their parents for support. Encouraging all children to achieve their highest potential without gender discrimination will result in all children obtaining a better life.

Hmong educators are the most vital component to teaching cultural awareness and gender equality. There are numerous Hmong who have achieved success in the education field. Yet, many of them have concealed critical information about the Hmong culture to the public. Educators from the Hmong community have an obligation to openly discuss the positives and negatives of the Hmong culture, and to help discover solutions for the entire community. Teaching awareness could lead to broader discussions, which inevitably would promote change.

\section{Recommendations for the Macrocommunity}

The United States is very diverse with many cultures and cultural practices. The corporate world must understand that today's leaders need to be successful in terms of cultural adaptability and cultural intelligence. Corporate trainers must integrate culturally based experiential learning tools to train employees, especially leaders.

The education system is a powerful entity that can be a critical base for learning about cultural competency. Schools need to honor every student's background and address the importance of culture. Whether it is through school events, sign displays, spirit days, or other efforts, all elementary and high schools need to consistently promote cultural awareness. Districts should provide frequent professional development opportunities for all staff and faculty to be culturally educated. Colleges also have an obligation to continue to foster cultural awareness, and must refine their teacher education preparation programs to address cultural competency as well as women's ways of knowing.

If all levels of the education system provided mentoring and networking opportunities, which are believed to positively impact women's career development (Higgins \& Kram, 2001), then minorities and specifically women would get the professional encouragement, advice, and affirmation needed to achieve success and leadership status. Community members must question their assumptions and research answers prior to forming stereotyped opinions. As Mee noted, some cultural practices are simply cultural responses in the best interest of the children, but they are inappropriate according to mainstream cultural practice. Having a full understanding of the 
intentions and the stories behind the action would enhance understanding and prevent wrong judgments.

\section{Recommendations for Aspiring Women Leaders}

Most of the participants warned that leadership is a lonely path to follow and even other leaders remain distant. Therefore, it is imperative that all women leaders or those women aspiring to be leaders elicit and sustain nurturing relationships. Form support groups and maintain monthly or even weekly meetings so that the leadership arena becomes more favorable for those already in leadership positions and those aspiring to be leaders. It is only through networking and supporting one another that women can increase representation in the leadership sector and empower other women to take on the challenge.

\section{Recommendations for Further Studies}

It is suggested that this study be utilized as a base for additional research. Researchers are encouraged to take on larger ethnographic studies covering more states and countries over a longer, more extended period of time, and with more leadership fields to fully identify the experiences of Hmong women leaders.

All the participants were born abroad. Further research could investigate whether or not Hmong women's motivations, values, and educational ideologies are related to the fact that they were involuntary immigrants. Since the age range for these participants was between 30 and 41 years of age, and the Hmong as a group have been residing in the United States for well over 30 years, are there other Hmong women leaders who were born in America that have achieved equal or higher status?

There are many Hmong cultural practices that are either still practiced, have been amended, or are on the verge of disappearing, such as filial piety, polygamy, underage marriage, and bride prices. Further studies centering on each of these cultural practices and how they impact Hmong children and adult learning, achievement, and success in educational and employment settings is recommended.

\section{Conclusion}

Kou Yang (personal communication, April 23, 2010) theorized that the reason why HmongAmerican women are now able to advance themselves more than men, when both genders probably received equal opportunities, was because Hmong women were culturally learning what Yang called project design. This is where parents had trained girls to be goal-oriented early on in their lives. Growing up, Hmong girls were expected to cook, clean, help with childcare, and other tasks. These were simple assignments but the ability to be task-oriented is a skill acquired that contributed to their ability as adults to transition from one setting to the next. While this is but one possible explanation for the success of these women, it was also clear that these women had an internal drive to be successful and were by their nature, goal oriented. Clearly, the nine participants in this study were also task-oriented and highly skilled at organizing, planning and networking. Also revealed through these women's stories was the fact that their paths toward and into leadership were long, hard fought, and supported by many along their individual journeys. 
It is hoped that through the stories of these nine women, other Hmong-American women will be inspired to become leaders, and those in both the Hmong-American community and the mainstream community will begin to openly support others who have the ability and desire to become leaders. The experiences lived by the women featured in this study can provide critical insights that could be beneficial to aspiring Hmong women leaders, and facilitate a deeper understanding of the Hmong-American culture and cultural practices. Finally, the findings of this study provide crucial information for supporting, advising, educating, and ultimately empowering all minority women towards achieving leadership roles.

\section{References}

Alon, I., \& Higgins, J. M. (2005). Global leadership success through emotional and cultural intelligences. Business Horizons, 48(6), 501-512.

American Community Survey Data (2009). American factfinder. Retrieved from http://hmongstudies.org/HmongACS2009.pdf

Banutu-Gomez, M. B. (2002). Leading and managing in developing countries: Challenge, growth and opportunities for twenty-first century organizations. Cross Cultural Management, 9(4), 29-41.

Bass, B. M. (1999). Two decades of research and development in transformational leadership. European Journal of Work and Organizational Psychology, 8(1), 9-32.

Belenky, M. F., Clinchy, B. M., Goldberger, N. R., \& Tarule, J. M. (1986). Women's ways of knowing: The development of self, voice, and mind. New York: Basic Books.

Bell, D., \& Nkomo, S. (2001). Our separate ways: Black and white women and the struggle for professional identity. Boston, MA: Harvard Business School Press.

Center for Hmong Studies (2011). Complete Hmong state totals 2010 census. Retrieved from http://tech.groups.yahoo.com/group/hmongstudies/message/470

Crampton, S. M., \& Mishra, J. M. (1999). Women in management. Public Personnel Management, 28(1), 87-107.

Creswell, J. W. (2003). Research design: Qualitative, quantitative, and mixed methods approaches (2nd ed.). Thousand Oaks, CA: Sage.

Donnelly, N. D. (1994). Changing lives of refugee Hmong women. Seattle, WA: University of Washington Press.

Earley, P. C. \& Mosakowski, E. (2004). Cultural intelligence. Harvard Business Review, 82(10), 139-146.

Gilika, M. M. (2009). Lived experiences of Batswana women in national leadership positions (Doctoral dissertation). Available from ProQuest Dissertations and Theses database. (UMI No. 3379266).

Goleman, D. (1998). What makes a leader? Harvard Business Review, 76(6), 93-102.

Guthrie, D., \& Roth, L. M. (1999). The state, courts, and equal opportunities for female CEO's in the U.S. organizations: Specifying institutional mechanisms. Social Forces, 78(2), 511-542.

Higgins, M. C., \& Kram, K. E. (2001). Reconceptualizing mentoring at work: A developmental network perspective. Academy of Management Review, 26(2), 264-288.

Hmong National Development \& Hmong Cultural and Resource Center. (2004). Hmong 2000 Census Publication: Data and analysis. Washington, DC: Author. Retrieved from http://hmongstudies.org/2000HmongCensusPublication.pdf 
Hofstede, G. (1991). Cultures and organizations: Software of the mind. London: McGraw-Hill. Huang, J. (n.d.). Filial piety in America. Retrieved from http://www.taoism.net/articles/xiao.htm Lee, M. N. M. (2005). The dream of the Hmong kingdom: Resistance, collaboration, and legitimacy under French colonialism (Doctoral dissertation). Available from ProQuest Dissertations and Theses database. (UMI No. 3186214).

Ling, H. (2008). Emerging voice: Experiences of underrepresented Asian Americans. New Brunswick, NJ: Rutgers University Press.

Love, P. G. \& Guthrie, V. L. (1999, Winter). Women's way of knowing. New Directions for Student Services, 88, 17-27.

McCormick-Higgins, J. A. (2005). Finding our way: Women's lived experiences leading into legislatures of Pennsylvania and Maryland (Doctoral dissertation). Available from ProQuest Dissertations and Theses database. (UMI No. 3173808).

McMaster, M., \& Randall, S. (1995). Issues in changing the gender culture of educational organizations. In B. Limerich \& B. Lingaid (Eds.), Gender and changing educational management: Second yearbook of the Australian Council for Educational Administration (pp. 7-66). Rydalmere, New South Wales: Hodder Education Press.

Montez, J. M. (1998). Asian/Pacific American women in higher education administration: Doubly bound, doubly scarce. Issues in Policy, No. 9. Pullman, Washington: Department of Educational Leadership and Counseling Psychology, College of Education, Washington State University.

Moua, L. (2011). Navigating multiple worlds: A qualitative study of the lived experiences of Hmong women leaders (Doctoral dissertation). Available from ProQuest Dissertations and Theses database. (UMI No. 3457292).

Moua, M. (2007). Leading between worlds: A multi-case study of bicultural women of color leaders (Doctoral dissertation). Available from ProQuest Dissertations and Theses database. (UMI No. 3287786).

Moua, T. (2003). The Hmong culture: Kinship, marriage \& family systems (Unpublished master's thesis). University of Wisconsin, Menomonie, Wisconsin.

Prosser, J. P. (2001). The synthesis of multiple identities: A qualitative study of the career development of prominent women of Asian descent (Doctoral dissertation). Available from ProQuest Dissertations and Theses database. (UMI No. 3035817).

Strauss, A. \& Corbin, J. (1990). Basics of qualitative research: Techniques and procedures for developing grounded theory. Newbury Park, CA: Sage.

Suárez-Orozco, C., Suárez-Orozco, M. M., \& Todorova, I. (2008). Learning a new land: Immigrant students in American society. Cambridge, MA: Harvard University Press.

Supple, A. J., McCoy, S. Z., \& Wang, Y. (2010). Parental influences on Hmong university students' success. Hmong Studies Journal, 11(1), 1-37.

Sykes, L. (2008). Emotional intelligence and women in leadership: Connections and applications. Ontario, Canada: Department of Food \& Nutritional Sciences, Brescia University College, University of Western Ontario. Retrieved from brescia.uwo.ca/iwil/events/conferences/lesley sykes.pdf

Toren, N. (1973). The bus driver: A study in role analysis. Human Relations, 26(1), 101-112.

Xiong, Z. B., Eliason, P. A., Detzner, D. F., \& Cleveland, M. J. (2005). Southeast Asian immigrants' perceptions of good adolescents and good parents. Journal of Psychology: Interdisciplinary and Applied, 139(2), 159-175. 
Wesley, S. M. (2008). The effect of gender and race on career advancement: A study of minority women in executive-level position within nonprofit organizations (Doctoral dissertation). Available from ProQuest Dissertations and Theses database. (UMI No. 3339302).

Yang, K. (2001). The Hmong in America: Twenty-five years after the U.S. Secret War in Laos. Journal of Asian American Studies, 4(2), 165-174.

Yang, K. (2004). Hmong movement: Hmong culture still lives. HSC Quarterly Publication, 3(8), 6-9.

Yang, K. (2008a). Generation/gender roles in Hmong society. Retrieved from http://hmongstudies.org/GenderinHmongSocietyPart1.pdf

Yang, K. (2008b). Hmong American contemporary experience. In H. Ling (Ed.), Emerging voices: Experiences of underrepresented Asian Americans (p. 236-254). New Brunswick, NJ: Rutgers University Press.

Yoshikawa, T. (2006). From a refugee camp to the Minnesota State Senate: A case study of a Hmong American woman's challenge. Hmong Studies Journal, 7(1), 1-23.

\section{About the Authors}

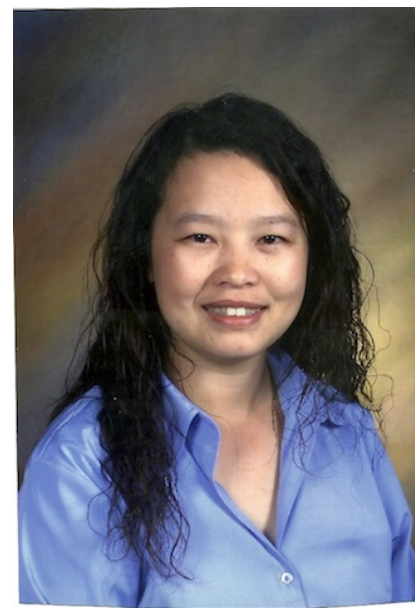

Born in Laos, Lena Moua's family was separated as a result of the Secret War. Her father disappeared when the family and the group they were traveling with were ambushed while trying to make their ways to the Thai border. Lena's mother brought her and her brother to the United States in 1980 when she was five years old. In the United States, Lena's mother was to be handed down to an uncle as the family accepted that her father would never return. Consequently, her mother refused the union and took the children to join her side of the family. At eight years old, Lena's mother remarried. Stress from having a stepfather among other things led Lena to choose marriage at the age of 14 to her husband who was only 16 years old. Today, the couple has been married for 23 years and has five children.

Lena was the first woman on both sides of her family to attend college. She graduated in 1998 from the University of the Pacific with a Bachelor of Arts in English. She continued her education at California State University, Stanislaus earning her Masters of Arts in Curriculum and Instruction in 2005 and a Doctor of Education in 2011. She has taught English as a high school teacher for 13 years as well as been a community college adjunct professor for three years. Presently, she works as a Literacy Coach for a high school.

In verifying her own experience as a Hmong woman, Lena conducted her Thesis on Hmong girls who were married and still in high school and her dissertation on Hmong women leaders. She had hoped that in doing so, the community would have a better, more in-depth understanding of the journey and obstacles that Hmong women endure as they balance a bicultural identity in the United States. 


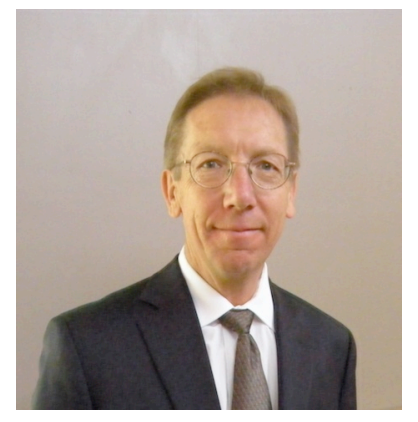

Jim Riggs has been a professor in the Department of Advanced Studies in Education at California State University, Stanislaus since 2008, where he teaches full-time in the University's Doctorate of Educational Leadership program and supervises research in the areas of higher education leadership, social foundations of education and student success. Areas of specialization and interest include educational policy, organizational change strategies, transformational learning, and leadership development. He has also taught at the University of the Pacific and Sacramento State University. Riggs has published articles and conducted presentations on a variety of topics including the future of leadership in higher education.

Dr. Riggs earned a doctorate in Higher Education Leadership and Curriculum from the University of Southern California and holds Masters and Bachelors degrees in music. Prior to joining the faculty at CSU Stanislaus, he served 10 years as the president of Columbia College, in Sonora, California. Other positions include Vice President of Education and Student Services at Lincoln Land Community College, Executive Dean at Yuba College, Dean of Instruction at Merced College, and Director of a branch campus of the University of Alaska. He began his career as a music and humanities instructor at a community college. 


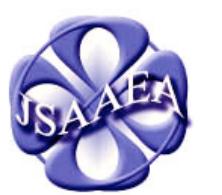

Volume 7 (2012)

\section{Journal of Southeast Asian American Education \& Advancement}

\author{
WwW.JSAAEA.org
}

\section{Editor}

Dr. Wayne E. Wright

University of Texas, San Antonio

\author{
Associate Editors \\ Dr. Chhany Sak-Humphry \\ University of Hawaii at Manoa
}

Dr. Phitsamay Sychitkokhong Uy

University of Massachusetts, Lowell

\section{Book Review Editor}

Dr. Vichet Chhuon

University of Minnesota

\section{Creative Works Editor \\ Bryan Thao Worra \\ Lao Assistance Center}

Special Advisor

Gregory Green

Curator, Echols Collection on Southeast Asia, Cornell University Library

\section{Journal Manager}

Sovicheth Boun

University of Texas, San Antonio
A peer-reviewed

scholarly journal published by the

National Association

for the Education \&

Advancement of

Cambodian, Laotian,

and Vietnamese

Americans (NAFEA)

Comments and questions for the editorial staff may be directed to jsaaea@1ists.sis.utsa.edu

\section{Editorial Review Board}

\author{
Dr. Steve Arounsack \\ California State University, Stanislaus \\ Dr. Phala Chea \\ Lowell Public Schools \\ Dr. Loan Dao \\ Cancer Prevention Institute of California \\ Dr. Changming Duan \\ University of Missouri, Kansas City \\ Dr. Jeremy Hein \\ University of Wisconsin - Eau Claire \\ Dr. Samlong Inthaly \\ Minneapolis Public Schools \\ Dr. Kevin K. Kumashiro \\ University of Illinois, Chicago
}

Dr. Carl L. Bankston III

Tulane University

Dr. George Chigas

University of Massachusetts, Lowell

Dr. Hien Duc Do

San Jose State University

Dr. Sophal Ear

U.S. Naval Postgraduate School

Dr. Nancy H. Hornberger

University of Pennsylvania

Dr. Peter Nien-Chu Kiang

University of Massachusetts, Boston

Dr. Ha Lam

Arizona State University 

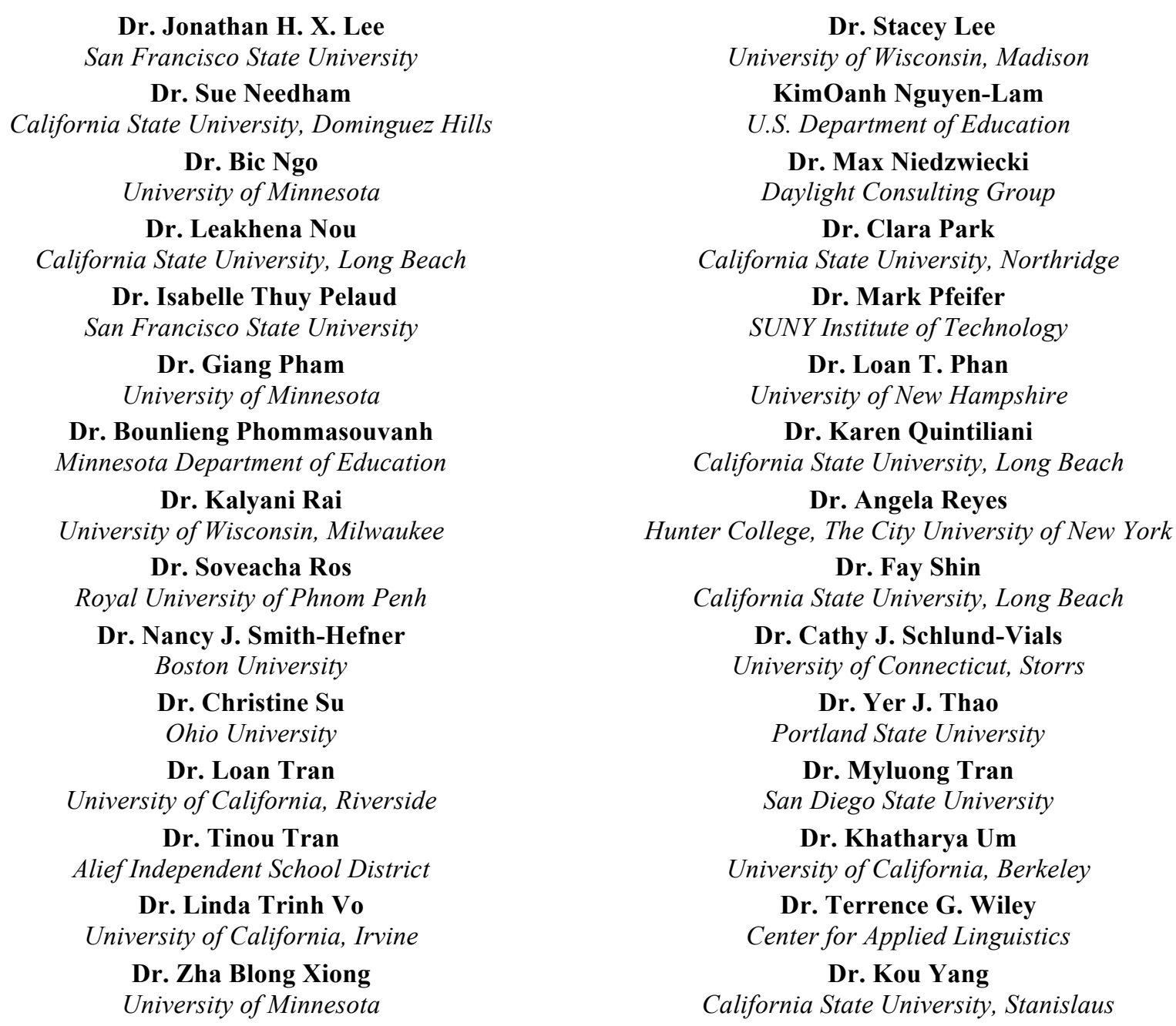

\section{Doctoral Student Editorial Review Board}

\author{
Keo Chea-Young \\ University of Pennsylvania \\ Ketmani Kouanchao \\ California State University, Fullerton \\ Ravy Lao \\ University of California, Santa Barbara \\ Thien-Huong Ninh \\ University of Southern California \\ Vanna Som \\ Harvard University \\ Krissyvan Truong \\ Claremount Graduate University \\ Yang Sao Xiong \\ University of California, Los Angeles
}

\author{
Annie BichLoan Duong \\ San Joaquin County Office of Education \\ Peter Tan Keo \\ Columbia University \\ Monirith Ly \\ Texas State University-San Marcos \\ Malaphone Phommasa \\ University of California, Santa Barbara \\ Alisia Tran \\ University of Minnesota \\ Silvy Un \\ University of Minnesota \\ Yeng Yang \\ University of Texas, San Antonio
}

